\title{
Obtaining Appropriate Design Parameters for Slopes in Weathered Saprolites
}

\author{
A.B. Fourie Australian Centre for Geomechanics, Australia
}

A. Haines SRK Consulting, Australia

\begin{abstract}
In many open pit operations, the near-surface profile exposes weathered material. If this weathered material is shallow, or still relatively competent, it presents no major problems and conventional design approaches remain relevant. However, in some cases the weathered profile may be very deep such that the material cannot be considered as rock. A common approach in these circumstances is to use designs based on soil mechanics principles. However, some recent failures of slopes in highly weathered, saprolitic profiles have highlighted inadequacies in this approach. A case study is presented from a mine in Guinea, West Africa, where the approach was to obtain very high quality block samples from the saprolitic zone for testing in the laboratory to obtain truly undisturbed material properties and ultimately provide much improved design parameters. The pit has now been in operation for over six years and the performance of the excavated slopes in the saprolitic material validated the approach adopted.
\end{abstract}

\section{Introduction}

In considering the design of slopes in open pit mining operations attention is focussed on the strength and stability of the intact or fractured rock masses. Unweathered rock usually makes up the vast majority of the profile exposed. In a few cases competent rock may extend to the ground surface, or where weathering is present it may only be for a few metres below the ground surface. It is perhaps because much previous experience has been gained at such sites that the tendency has emerged to simply refer to anything that is not competent rock as "overburden". However, in many parts of the world, this 'overburden' can extend to significant depth and as a result can be a major impediment to successful mining.

This paper focuses on near-surface materials, concentrating on situations where the parent rock has undergone significant alteration due to weathering and can no longer be considered in rock mechanics terms. It argues that when designing slopes in highly weathered material using conventional soil mechanics approaches there is a need to develop specific sampling and testing procedures.

\section{What is a residual soil?}

A useful geotechnical definition of a residual soil was given by Blight (1997) as, 'a soil-like material derived from the in situ weathering and decomposition of rock which has not been transported from its original location'. The key phrase in this definition is 'soil-like'. As argued in this paper, although a residual soil has many mechanical properties that are similar to those of transported soils, there are aspects that differentiate these materials from conventional soils and therefore simply adopting soil mechanics approaches can be misleading.

Transported soils have, by their nature, undergone substantial textural reorganisation and remnant parent rock structures have been destroyed. The classical soil mechanics theories, such as those dealing with effective stresses, consolidation and critical state theory have all been developed based on the testing of transported soils. While the theories remain valid for residual soils, cognisance of certain aspects of residual soil behaviour must be recognised in order to utilise these theories rationally.

Residual soils tend to retain some features of the parent rock from which they were derived, both texturally such as dominant fractures or fissures and a stress history memory. The latter may also result from residual cementing, or bonding, which provides some degree of true cohesion between particles. As a result of these cemented bonds, residual soils may show some features that are distinctly non soil-like (i.e. are more rock- 
like). For example, they may retain a preconsolidation effect, even if erosion of overburden has occurred. This is because the cemented bonds may prevent void ratio changes associated with loading and unloading. An example of the effect of cemented bonds is shown in Figure 1, where the same soil in an uncemented state shows a completely different loading path in an oedometer than does a soil where bonding is present. Other apparently anomalous consequences of the retention of cemented bonds can be the higher than expected void ratios. It is not uncommon to find void ratios in excess of one or even two, as discussed later.

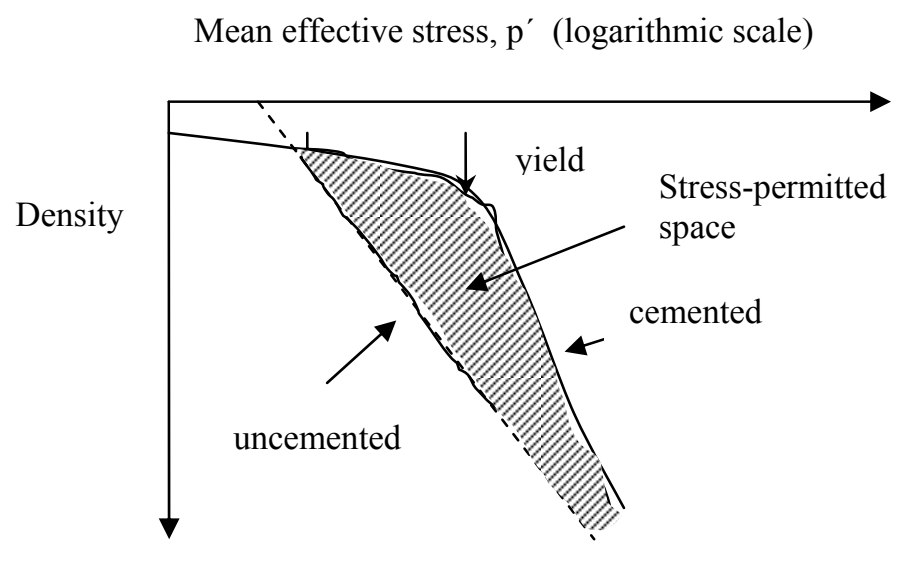

Figure 1 Illustration of how cementing (residual bonds) results in much reduced compressibility of a residual soil below the yield point during loading in an oedometer (1-D compression) test

These aspects are important because they impact on the choice of appropriate design parameters, in particular the choice of strength parameters. The fact that we are dealing with a soil-like material, where the effect of pore water pressure cannot be ignored, means that use of a total stress approach is inadequate. It is necessary to think in terms of effective stresses, but even then the impact of residual structure must be remembered. In this paper, nature and performance of residual soils from a mine site in West Africa are discussed. The soils are considered to be saprolites, for which the definition used is, "thoroughly decomposed rock, a clay rich soil formed in place by chemical weathering of igneous or metamorphic rocks" (Geological Society Engineering Group Working Party, 1990).

\section{Do micro-features or macro-features dominate?}

When thinking of material as being 'soil-like', the inference is that it behaves as a continuum. For example, characterisation of water flow through the material would be in terms of a hydraulic conductivity that describes the rate of flow through the pore voids. Similarly strength would be characterised in terms of a continuum approach, where the shear strength is mobilised through an essentially intact matrix of particulate material. In comparison, when considering a competent rock mass, it would be more usual to consider water flow along joints or fissures, and similarly to be more concerned about the strength properties of these discrete features than the properties of the intact rock material. When dealing with saprolites, it seems prudent to consider both these possibilities and to design for the worst.

\subsection{Choice of appropriate permeability}

It is certainly much easier to test the intact (continuum) permeability of a saprolite than it is to test the permeability of a residual discontinuity (assuming it can be identified in the first place). However, there is much evidence, both anecdotal and published, that stormwater can penetrate saprolite profiles more rapidly than expected, causing rapid changes in pore water conditions, often leading to slope instabilities (Gerscovich et al., 2006). Such rapid inflow of water can only occur along discontinuities present and therefore they need to be characterised. There are many studies of the effect of rainfall on the stability of natural slopes in tropical and residual soils (Lumb, 1975; Fourie, 1996). The lessons from these studies are equally relevant to excavated slopes such as those in open-pit mining. For example, it is now accepted that it 
is inappropriate to consider potential rainfall impacts only in terms of rainfall intensity (such as setting a threshold intensity above which potential instability may be expected), but rather that firstly antecedent conditions are important, and that secondly both intensity and duration are important contributors to potential instability. Recognising this effect, design and management of an open pit operation can be tailored to suit local conditions. It may be possible, for example to:

- Programme parts of the pit for excavation only during the dry season, thereby avoiding activity in the period when sudden and unpredictable rainfall events are possible.

- Install systems that monitor changes in pore water pressure and thereby track the antecedent moisture conditions in a slope, providing early warning of potential problems. The difficulty with this technique is the non-continuum nature of many saprolite profiles mentioned earlier, which makes it difficult to know where to locate a piezometer to provide a representative measure of in-situ pore pressures.

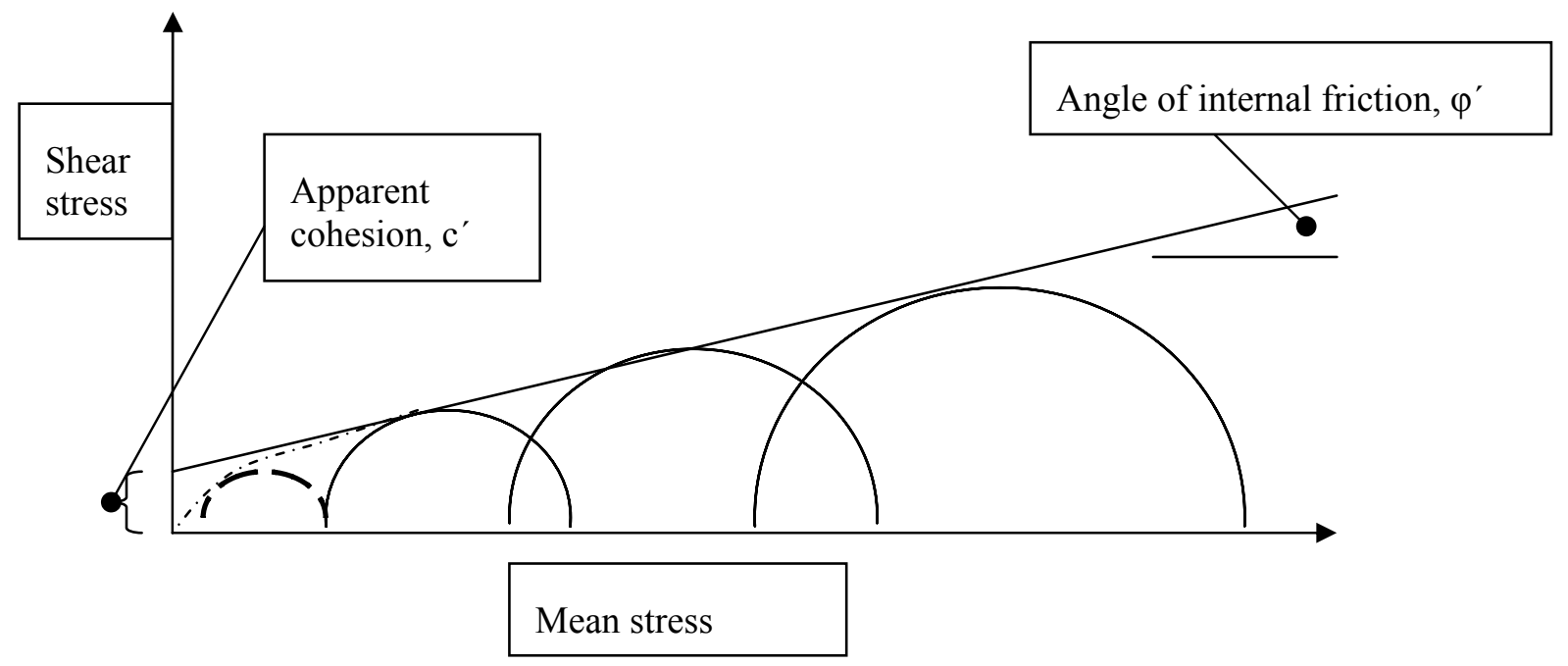

Figure 2 Illustration of definition of effective stress strength parameters

\subsection{Choice of appropriate strength parameters}

In the analysis of soil slopes using limit equilibrium methods, the required strength parameters for an effective stress analysis are the angle of internal friction, $\varphi^{\prime}$, and the apparent cohesion, $c^{\prime}$. It must be emphasised that $\mathrm{c}^{\prime}$ is not a true cohesion, but is in fact merely an artefact of the way that strength test results are plotted. This is explained in Figure 2, which shows typical results from triaxial compression tests on three specimens consolidated to different initial stresses, shown as the solid semi-circles. The failure envelope that confines these Mohr circles is a straight line, as shown, which has an intercept on the y-axis which is the apparent cohesion.

However, this intercept is merely a convenient way of defining a straight line. There is now much evidence in the geotechnical literature that under low effective stresses, the mobilised strength can be in fact lower than that given by the straight line envelope shown in Figure 2. In this case the true failure envelope is the one tangential to the circle shown dotted in Figure 2. Despite this anomaly, the use of apparent cohesion in a straight-line fit of strength data has served the industry well and is now universally accepted. It is discussed here in some detail because in most saprolites the y-axis intercept is a true cohesion, arising from the cemented bonds referred to earlier, and therefore can be relied on even under low stress conditions.

The shear strength of a soil, $\tau_{\mathrm{f}}$, is usually defined as:

$$
\tau_{f}=c^{\prime}+\sigma^{\prime} \tan \phi^{\prime}
$$

where $\sigma^{\prime}$ is the effective stress acting normal to the plane on which the shear strength is mobilised. 
When dealing with unsaturated soils, such as saprolites, there is another contributor to shear strength, which is the negative pore water pressure, or suction, that occurs when the degree of saturation falls below about $85 \%$. Referred to as matrix suction, it has the effect of increasing the effective stress, $\sigma^{\prime}$, referred to above and therefore the available shear strength. It is because of this effect that when dry many soil slopes are able to remain stable at slope angles that are steeper than would be predicted by Equation 1.

It also explains why many of these slopes fail during periods of heavy or prolonged rainfall, even when a rise in water table (and generation of excess positive pore water pressure) does not occur. The degree of saturation of the soil increases, without necessarily reaching $100 \%$, which causes the matrix suction to decrease and the additional strength component to disappear, ultimately resulting in failure of the slope. It may be that a particular slope remains stable for many decades at an angle that is in violation of Equation 1, but when subjected to a period of particularly severe rainfall (sometimes associated with anthropogenic effects, such as toe excavation or vegetation denudation), it fails suddenly. So where does that leave us with regard to correctly defining appropriate strength parameters? It seems prudent to not rely on the matrix suction effect unless one can be certain that all necessary work can be completed during the dry season, and to regard this component of strength as an additional factor of safety during the dry season. This means that the conventional strength parameters $\mathrm{c}^{\prime}$ and $\varphi^{\prime}$ remain the parameters that need to be determined for stability evaluations.

\subsubsection{Taking account of brittleness when defining strength parameters}

Unfortunately there is another potential issue to be considered when defining an appropriate shear strength for use in limit equilibrium stability evaluations. This relates to the potential brittleness, or strain softening, that is characteristic of many saprolites. Strain softening is well known in the rock mechanics literature and the phenomenon is no different in soil mechanics, as illustrated in Figure 3. This shows a typical stress-strain plot for a test on a saprolite. As shown, the shear stress reaches a peak, indicated as $\tau_{\mathrm{p}}$, after which the available shear strength decreases until a residual value, $\tau_{\mathrm{r}}$, is reached. When plotting the Mohr stress circles such as shown in Figure 2, the question then arises which value of shear strength to use, the peak or the residual? Using the peak value may be unsafe, because if the peak strength is mobilised, even only locally, the load carrying capacity in this region will decrease and progressive failure of the entire slope may occur very suddenly (Troncone, 2005). However, using the residual strength will result in the requirement of very shallow-angled slopes, which will be not only expensive but also perhaps totally unnecessary. After all, we are then ignoring two factors that result in a strength that is higher than the residual value - the peak strength and the contribution due to matrix suction.

The brittleness of many saprolites can result in a distortion of the available shear strength, if suitable sampling and testing techniques are not used. The vast majority of soil samples for strength testing are recovered in the field using one of a variety of tube sampling techniques. The assumption is that if this process is carried out carefully (which is itself a rather dubious assumption) the resulting soil samples will represent undisturbed conditions and when tested will provide representative strengths. However, as shown by Baligh (1985), the compressive strains induced by very careful insertion of a thin walled sampling tube are still of the order of 2 to $4 \%$. This may be sufficient to cause enough compression of the residual soil sample to severely damage the cemented bonds, resulting in densification of the sample. If the increase in the sample density is significant, subsequent triaxial testing will not display the brittle behaviour illustrated in Figure 3, as the sample will be dilative (due to the higher density) virtually from the start of testing, which will imply greater strength than is actually available. The brittleness, which can have severe consequences, will be totally overlooked as a result. 


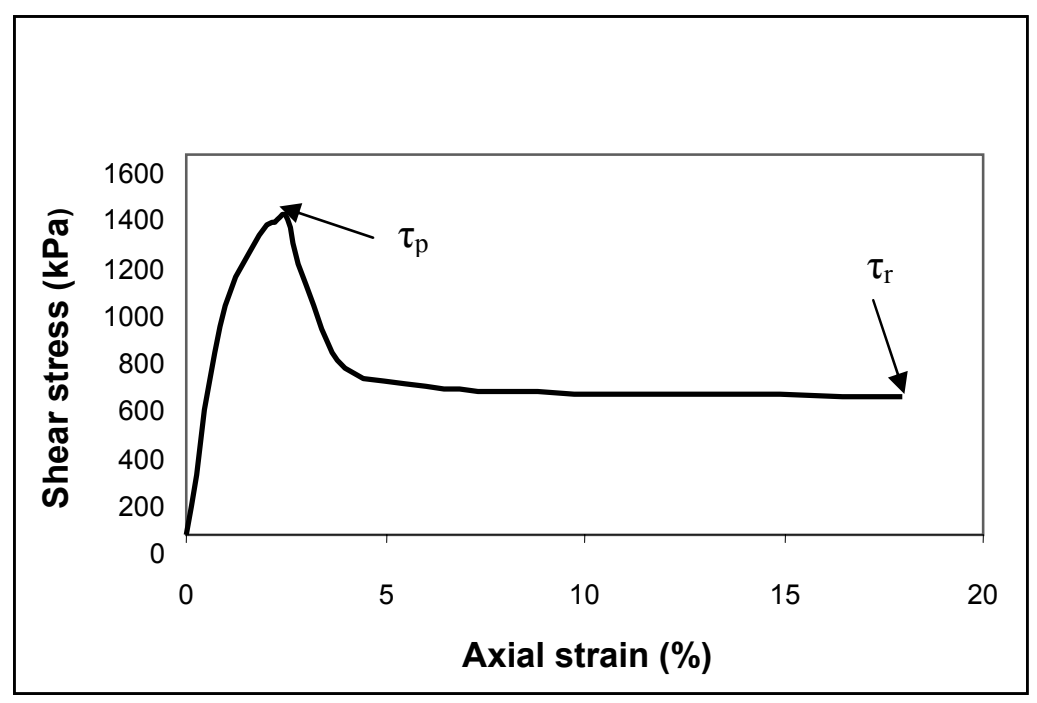

Figure 3 Illustration of strain softening and the difference in peak and residual strength

\section{Appropriate sampling procedures to ensure samples are representative}

In the absence of a comprehensive comparison that shows otherwise, the use of block samples rather than tube or piston samples for the collection of undisturbed soil samples would seem to be the sensible approach to use when dealing with saprolites. The disadvantages of block sampling are the time required to obtain a decent block, and the fact that samples cannot be recovered from the base of a borehole, but rather require an open excavation with a few square metres of working area. However, given the high cost of even conventional sampling procedures, the potential for obtaining truly representative samples for testing and design purposes will far outweigh these negative aspects. This approach does not address the issue of obtaining samples of discontinuities that may exist between blocks of relatively intact saprolites. The question of characterising the strengths of discontinuities in residual soils, which can of course be very important in the overall slope behaviour, have not been investigated in great detail.

\section{Case history from West Africa}

The following case history presents an example of a suitable sampling and testing programme for determining saprolite properties.

\subsection{Background to the mining conditions}

Following a slope failure in 1998 at the Sanu Tinti Stage 1 pit in Guinea, which was owned by Société Ashanti Goldfields De Guinée (SAG), an investigation was initiated together with a re-design of the Sanu Tinti Stage 2 and Eureka open pits. The Stage 1 pit at Sanu Tinti had failed on both the footwall and hangingwall slopes, which were both in oxidised saprolite. The footwall slope had failed as a classical circular slip along its entire $250 \mathrm{~m}$ length while the hangingwall had failed as discrete wedge-style blocks.

The existing design for the saprolites was for overall slope angles of between $42^{\circ}$ and $55^{\circ}$ for the slope above the ground water surface and slopes of between $22^{\circ}$ and $35^{\circ}$ for slopes below. The higher values were for slopes $<25 \mathrm{~m}$ in height and the lower values were for slopes up to $100 \mathrm{~m}$ in height. The bench face angle was recommended as $68^{\circ}$ with a $10 \mathrm{~m}$ bench height above the ground water surface and $5 \mathrm{~m}$ below.

A view of the footwall slope failure is provided in Figure 4. The dark line of vegetation curving half way down the face was originally at ground surface. The slope height shown in the figure is approximately $50 \mathrm{~m}$. 


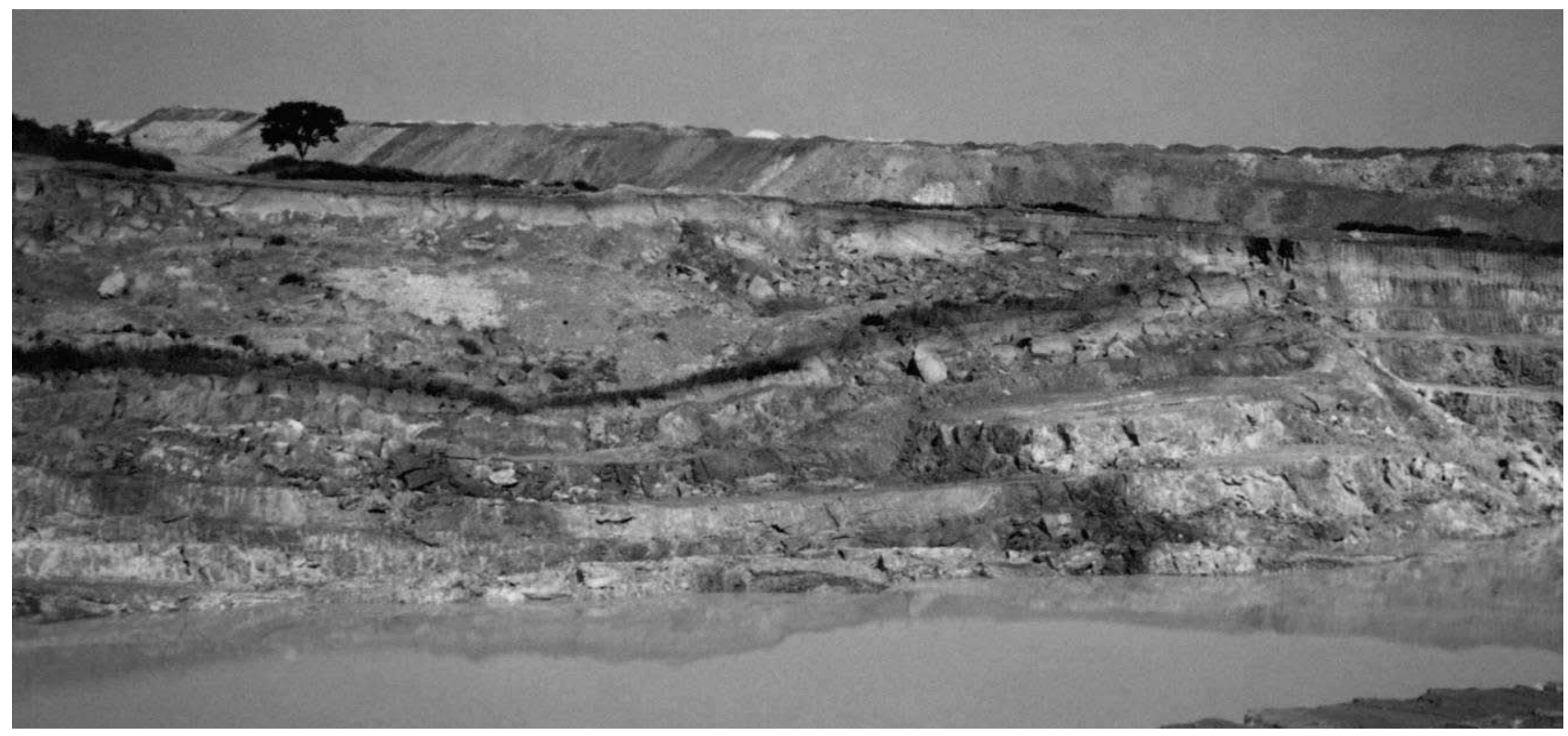

Figure 4 View of the footwall slope following the failure at Sanu Tinti in 1998

Saprolite is a very unique material as it has the appearance and behaviour of a material ranging between a soil and a weak rock. It also alters its behaviour, sometimes dramatically as in the case of Sanu Tinti, from the dry to the wet season due to rapid changes in the degree of saturation in the tropical climate of West Africa. As each saprolite is different, with its characteristics dependent on its geological origin from typically fine grained source rock, it is important not to make generalisations regarding its material properties and not to use data from a different, or even nearby, source.

The Sanu Tinti footwall started to show signs of instability towards the end of May 1998 with tension cracks appearing along the pit crest. Following slumping along the length of the slope there was a gradual failure of a shallow circular nature resulting in major vertical and horizontal displacements of the full slope height of approximately $50 \mathrm{~m}$. In effect, the entire slope slowly rotated, as an intact mass, into the floor of the pit. The berms were mostly intact, although fissured, but were raised and tilted backwards following the circular rotation. A cross section through the footwall slope showing the before and after slope profile is provided in Figure 5.

A complete physical inspection of the existing pit slopes was carried out to distinguish between those that had failed and those that were stable. The outcome of this census, which relates slope height with slope angle, is provided in Figure 6. The initial design curve that was produced from this work, for both bench stack and overall slope, proved to be very useful in the early stage of the investigation and provided an initial empirical base for future design work. What was initially evident from the curve was that any slope greater than approximately $70 \mathrm{~m}$ in height should not be steeper than $20^{\circ}$. An overview of the failures indicated that a number of factors had contributed to the current situation. These were as follows:

- A very weak saprolite with the principal horizontal stress acting perpendicular to the slope.

- The presence of major structures acting as sliding/release planes at each end of the footwall failure.

- Ponding of ground water at the base of the slope.

- No surface water control measures or active dewatering.

- Heavy seasonal rainfall some days just prior to failure.

- Bench stack and overall slope angles in excess of the slope shear strength capacity for the corresponding slope height. 


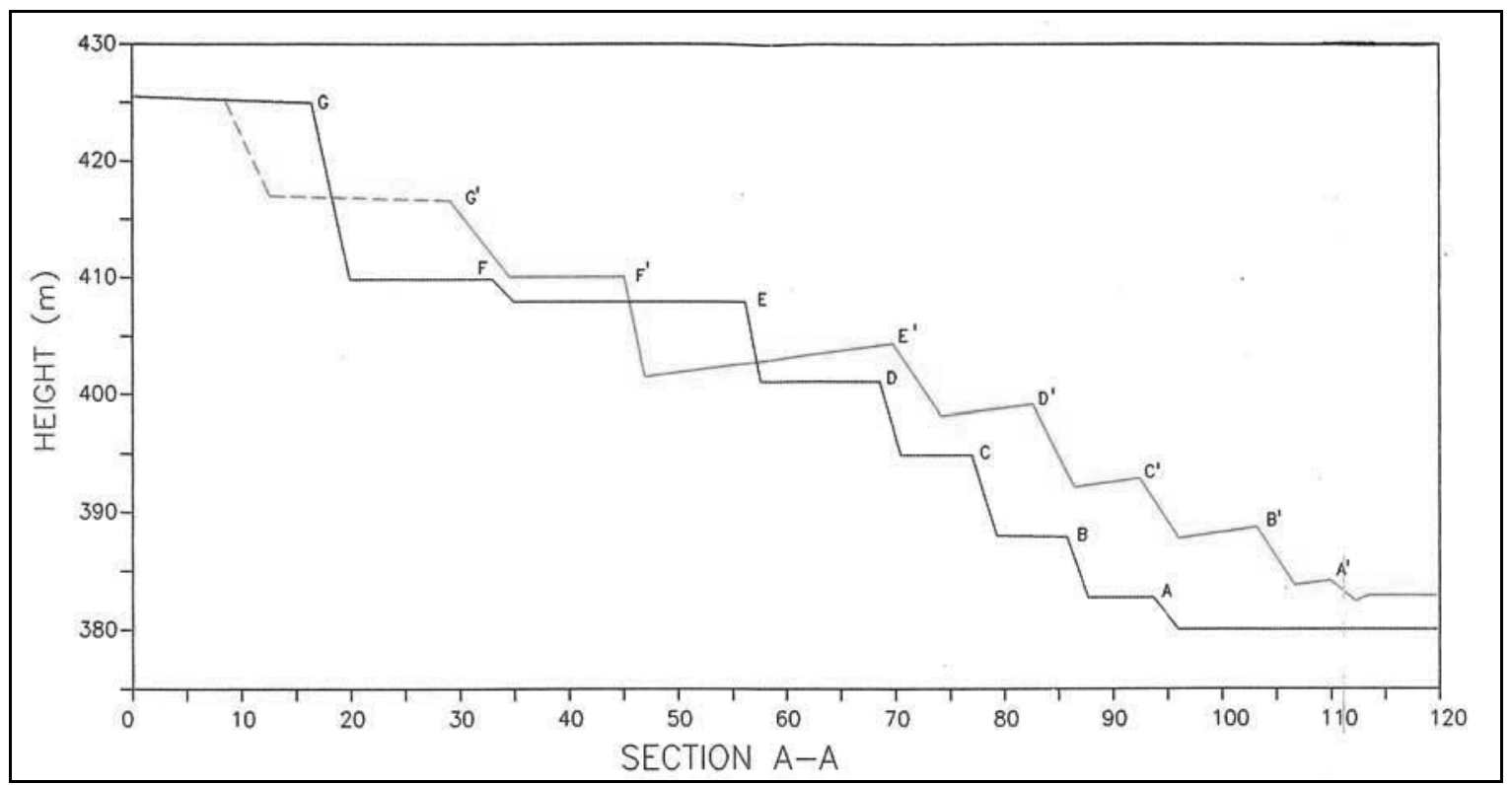

Figure 5 Profile through the footwall slope at the Sanu Tinti open pit (illustrating the profile before and after the slope failure)

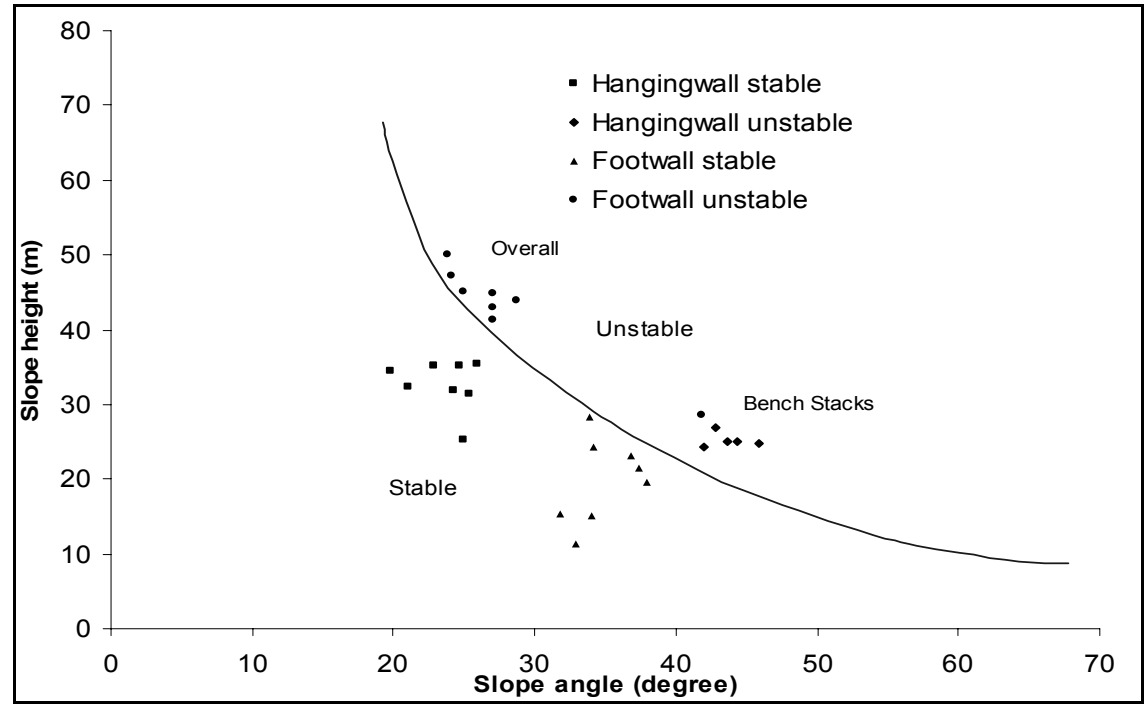

Figure 6 Initial slope design curve for Sanu Tinti (based on existing slope stability conditions)

\subsection{Block sampling of the saprolites}

Further development of the open pit mining operation at Sanu Tinti required that high quality samples of the saprolites be obtained for determination of appropriate design parameters. The ultimate depths of mining within the saprolites at the site were as much as $160 \mathrm{~m}$, and the need to ensure the stability of slopes in this material was clearly paramount Mining to date had been mostly within the brightly coloured, oxidised saprolite horizon and partially into the light grey, unoxidised saprolite zone below. Below the unoxidised saprolite zone lies a transitional horizon of saprock.

Conventional tube sampling procedures were rejected in favour of block sampling procedures and three blocks in all were recovered from three exposures in two pits. Two of these were from the Sanu Tinti (ST) pit and one from the nearby proposed Eureka Hill (EH) pit (both being part of the Siguiri complex). The oxidised saprolite blocks were typically cubic, with side lengths of about $40 \mathrm{~cm}$. After excavating and trimming the blocks, they were coated with layers of wax and plastic film, before being packed into individual wooden crates that were then filled with sawdust. The crates were airfreighted to Johannesburg for 
testing at the laboratories of the University of the Witwatersrand. The process of transporting the samples across international borders in Africa was not without its impediments and is not an undertaking to be taken lightly. The following sections describe the results of the experimental study on the Siguiri block sampled material.

\subsection{Description of material and index test results}

Table 1 contains the key characteristics obtained from laboratory tests on the saprolite from Guinea and Figure 7 shows the particle size distribution curves for the three materials.

The saprolites at the mine sites were derived from metasediments, predominantly from sandstone, siltstone and mudstone beds. These are weak materials and can easily be cut with small hand tools, as was done for the block samples. A disturbed sample held in the open hand and put under running water will disperse easily.

Table 1 Key characteristics of saprolite from the mine sites

\begin{tabular}{lccc}
\hline Characteristic & ST 1 & ST 2 & EH \\
& Footwall Slope & Hangingwall Slope & \\
\hline Liquid limit (\%) & 53 & 46 & $41-45$ \\
Plasticity index (\%) & 36 & 23 & $33-35$ \\
Specific gravity & 2.82 & 2.71 & 2.7 \\
Void ratio & $0.83-0.92$ & $0.48-0.52$ & $0.78-1.09$ \\
In-situ degree of saturation- & 52 & 63 & 48 \\
\% - dry season & 16 & 12 & $13-15$ \\
Corresponding water content $(\%)$ & - & - & 89 \\
\% - wet season & ML & CL & ML \\
USCS classification & mica & Quartz, montmorillonite & Quartz, kaolinite, \\
Mineralogy $($ in order of decreasing & Kaolinite, Quartz, & illite, microcline \\
proportion) & - & - & $3 \times 10^{-8}$ \\
Intact permeability (m/sec) & 106 & 227 & 28 \\
Cohesion $(\mathrm{kPa}):$ see note & 20 & 22 & 21 \\
Friction angle $\left({ }^{\circ}\right)$ : see note & & & \\
\hline
\end{tabular}

Note: the laboratory derived shear strength parameters are for saturated, consolidated and drained test conditions (at confining pressures of 500, $600 \& 800 \mathrm{kPa}$ ).

It should be mentioned here that particular care was taken when preparing samples for the Atterberg Limit tests (the liquid and plastic limits) and the particle size distribution tests (with no coarse fraction removed). As discussed by Fourie (1997), there is ample evidence in the literature that oven drying of these soils results in major alterations to the material structure, causing inconsistent test results when the above tests are conducted. All samples were therefore air dried before testing (which takes longer than oven drying).

The first thing to highlight is that the materials are all essentially clayey silts (ML/CL borderline), with the percentage of silt typically between about 75 and $80 \%$. The clay fraction is, however, consistently significant and probably plays a major role in the strength behaviour of the saprolite. For example, the friction angle values shown in Table 1 are much lower than would be expected for a silty material, an effect that is due to the high clay content. 


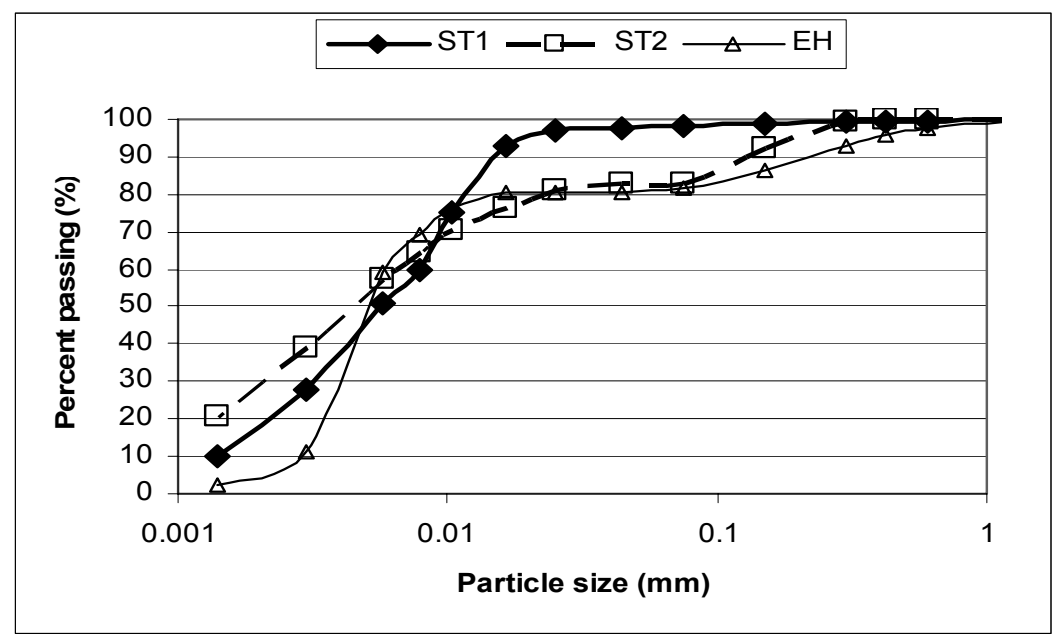

Figure 7 Particle size distribution curves for three saprolite materials from Guinea, West Africa

Although only one complete test was carried out, the high in-situ permeability is consistent with that reported for many sites in saprolitic soils around the world. It is also consistent with the coefficient of consolidation that was determined from one-dimensional consolidation tests and was very high, around $350 \mathrm{~m}^{2} /$ year. Information on the change in degree of saturation at the Eureka Hills site (see Table 1) illustrates the effect referred to earlier, whereby a significant change in moisture content occurs during the rainy season, potentially destroying the strength contribution from the matrix suction that occurs in drier material.

\subsection{Shear strength parameters}

An example of the results that were typically obtained from consolidated, drained triaxial tests are shown in Figure 8, where Figure 8a shows the shear stress-strain data and Figure 8b shows the variation of volumetric strain with axial strain. As can be seen from Figure 8a, peak shear strengths are reached at about 2 to $4 \%$ axial strain, after which there is a drop in the mobilised shear resistance, with residual shear strengths being about half of the peak values. Poor quality sampling techniques would, in all likelihood, have damaged the structure of the samples to such an extent that this brittleness may well have been disguised. In Figure $8 \mathrm{~b}$, the post-peak behaviour can be seen to be dilative, particularly at the lower value of confining stress, probably due to the initial (pre-peak) compression of the specimens causing the density to increase to a point where dilation becomes possible. It is also important to note that no dilation occurs prior to the peak strength being reached, which implies that the true (bond-induced) cohesion must first be overcome before the large strain residual frictional strength is mobilised.

In addition to conventional triaxial and shear box tests, two triaxial tests were carried out in which a negative pore water pressure was applied to the base of the specimen being tested, using a high air-entry ceramic disk, which meant that negative pore pressures could be ensured throughout the shearing phase. In these tests, the maximum shear strength was found to be between 10 and $60 \%$ higher than the maximum strength of saturated specimens. As discussed before, the matrix suction has the effect of increasing the mean effective stress throughout the specimen, meaning that shear strengths can be higher. Once again, it must be emphasised that this extra component of strength may well be transient, occurring only during the dry season, and cannot necessarily be relied on for design purposes. 


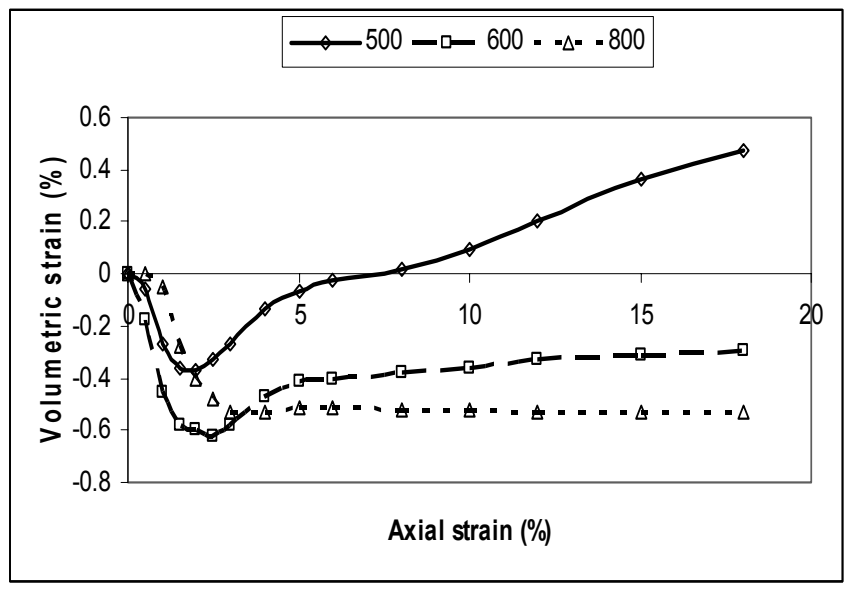

(a)

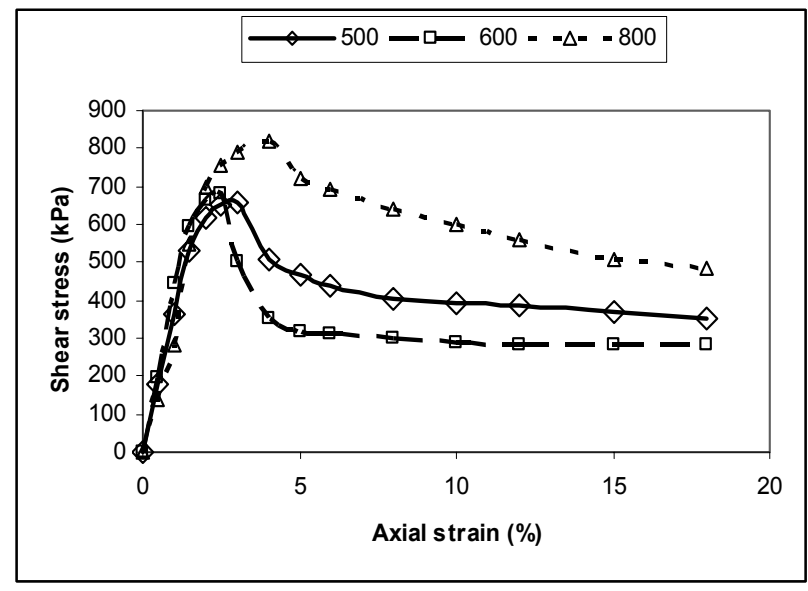

(b)

Figure 8 Results from consolidated, drained triaxial compressive test, in terms of shear stress versus axial strain (a), and volumetric strain versus axial strain (b). Numbers in legend refer to the effective confining stress in the triaxial test in $\mathrm{kPa}$

\subsection{Slope design considerations}

A series of slope stability analyses were carried out to determine the appropriate slope angle, slope height and drainage constraints to achieve stable slopes. Both 2D FLAC and limiting equilibrium analyses were carried out to generate a set of slope design recommendations. The design section used for these analyses, illustrating both the existing and proposed final pit slopes and dewatering scenarios, is shown on Figure 9.

In Figure 9; N: is a ground water surface close to the pit wall, 50: represents a ground water surface at $50 \mathrm{~m}$ behind the pit wall, HW: is the hangingwall slope and FW: is the footwall slope.

The back analyses of the actual footwall failure at Sanu Tinti indicated that the shear strength parameters of the saprolite at the time of failure were very similar to the lower bound value of those derived from the laboratory testing. The back analyses for the conditions present in the footwall slope at the time of failure resulted in a value of $10 \mathrm{kPa}$ cohesion and $22^{\circ}$ friction. This value is considered indicative of the mass behaviour of the saprolite and could reflect the influence of smooth relic structures that may comprise some portions of the failure surface. Due to the bedded nature of the original metasediment it is possible that these may have acted as planes of preferential weakness during the movement. However, it was not possible to examine the actual failure surface. In addition, major fault surfaces were acting as release planes at either end of the slip.

The laboratory testing of the intact material (for saturated, drained conditions) produced maximum values of $106 \mathrm{kPa}$ cohesion and $20^{\circ}$ friction, although the test from Eureka Hill gave a cohesion value as low as $20 \mathrm{kPa}$, with friction angles once again near $20^{\circ}$. The higher cohesion value is indicative of the material without relic structures and remote from major discontinuities. It is evident that water management and drainage can have a beneficial impact on the shear strength and resultant performance of the pit slopes. The resultant overall slope angle for the final $100 \mathrm{~m}$ high pit slope would be $25^{\circ}$ (with drainage) and $18^{\circ}$ (limited drainage). 


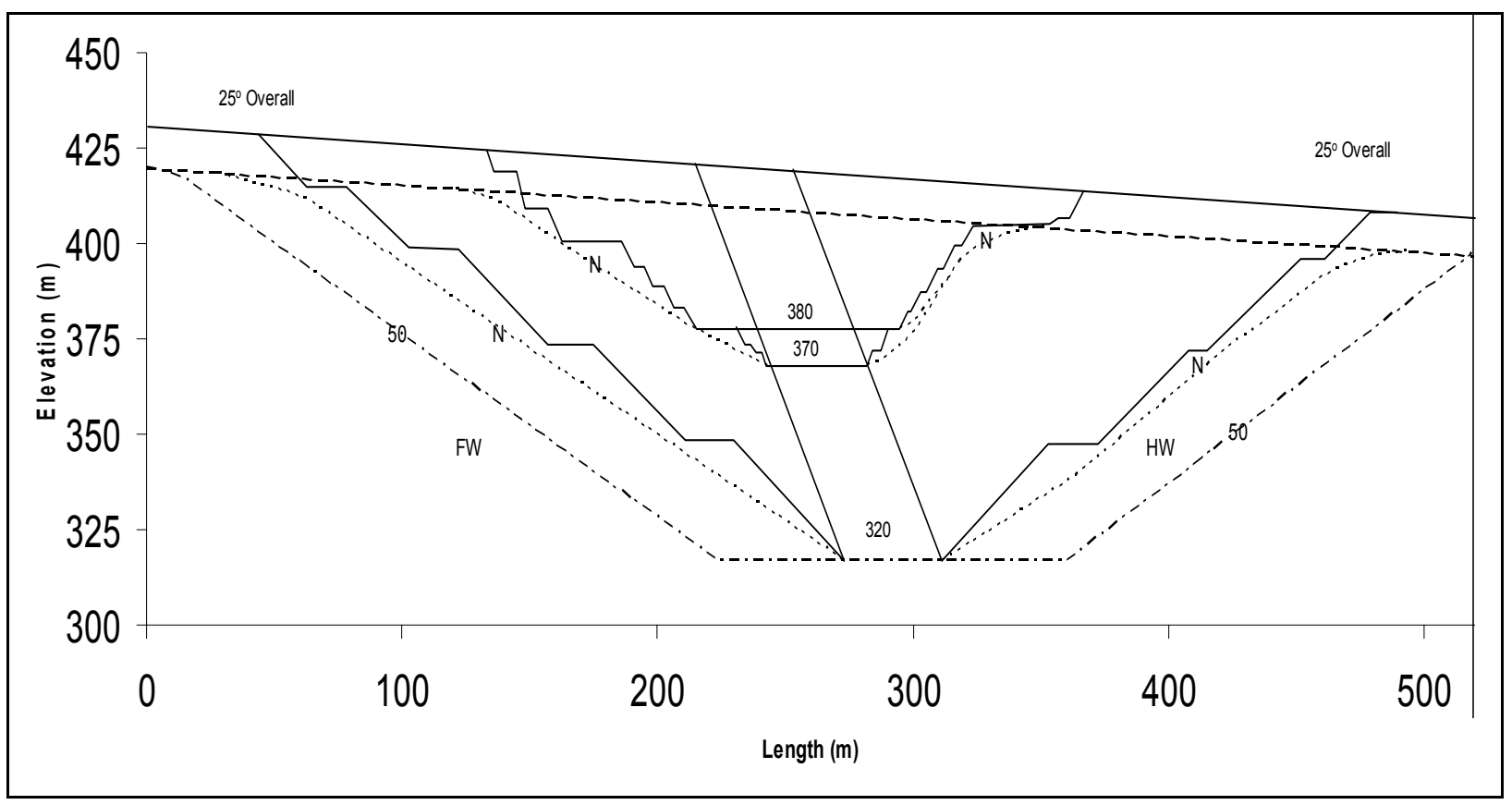

\section{Figure 9 Slope stability design section}

\section{Conclusions}

Selection of shear strength parameters for the design of open pit slopes in saprolites is not straightforward. The recommended approach outlined in this paper is to utilise results from laboratory tests of specimens taken from high quality block samples. The results from the laboratory testing were found to agree extremely well (using $10 \mathrm{kPa}$ cohesion) with those from the back-analyses of failed sections. The process of excavating, trimming and transporting blocks of undisturbed soil is not cheap or easy. It requires personnel who appreciate the importance of the sampling procedure being adopted, as it is vital that truly undisturbed samples are recovered, otherwise the entire exercise is futile. However, the potential benefits of carrying out such a sampling procedure, and of undertaking appropriate laboratory testing on the recovered samples, should prove to far outweigh the inconveniences. This was certainly the case at Siguiri, where a high level of confidence could be placed on the design parameters that were finally derived.

The test results also served to highlight potential strain softening in the saprolites and account was taken of this behaviour in the design assessment. Without the benefit of high quality sampling and testing, the strain softening nature of the soil could have been masked and higher values of the angle of internal friction (or lower cohesion) would have been (incorrectly) derived.

The pit has now been in operation for over six years and the good performance of the excavated slopes in the saprolitic material has validated the approach adopted. The benefits of this study are that it clearly shows that for major excavations in saprolitic material, and indeed it is true for most residual soils, a simplistic approach to shear strength selection is inappropriate and likely to be unconservative. This is because higher estimates of both cohesion and the angle of internal friction may be obtained. A possible compensating factor is that the contribution of matrix suction to the shear strength tends to be neglected, because conventional laboratory testing is usually carried out under saturated conditions. The contribution of suction to shear strength can be significant, and explains why some slopes have been observed to be stable at slope angles in excess of the limiting value obtained from limit equilibrium analyses. Unfortunately this component of strength cannot be guaranteed in perpetuity and is often destroyed by the ingress of water, usually under conditions of prolonged or heavy rainfall. While this can be addressed to some extent through the provision of suitable drainage structures, the issue is complicated by the often widespread occurrence of residual joints or other discontinuities. Indeed, the issue of residual discontinuities (which is what the discontinuities in the oxide essentially are), has not been addressed in this paper, which has concentrated on obtaining accurate strength properties for intact oxide material. It is acknowledged that these discontinuities may, in certain circumstances, dominate behaviour of a slope in oxide material. However, we are not aware of any testing 
programmes that have attempted to address this issue in any depth and believe that the procedures described in this paper would be equally relevant to the determination of discontinuity strength parameters. Given the increasing development of deep open pits in areas of the world where significant depths of saprolitic and residual soils exist, there will doubtless be more and more attention paid to the unique engineering properties of these materials in the future.

\section{Acknowledgements}

The authors would like to thank the mine management at Société Ashanti Goldfields De Guinée (SAG) for their permission to publish the case history study. Allan Haines would like to thank the staff at SRK Consulting in Perth for their assistance with the preparation of this paper.

\section{References}

Baligh, M.M. (1985) Strain path method. Journal of Geotechnical Engineering, ASCE 111, pp. 1108-1136.

Blight, G.E. (1997). Origin and formation of residual soils. Chapter 1 in: Mechanics of Residual Soils, Ed. G.E. Blight, Balkema, Rotterdam.

Fourie, A.B. (1996) Predicting rainfall-induced slope instability. Proceedings of the Institution of Civil Engineers, Geotechnical Engineering 119, pp. 211-218.

Fourie, A.B. (1997) Classification and index tests, Chapter 5 in: Mechanics of Residual Soils, G.E. Blight (editor), A.A. Balkema, 237 p.

Geological Society Engineering Working Party (1990) Report: Tropical Residual Soils. The Quarterly Journal of Engineering Geology 23(1), pp. 1-101.

Gerscovich, D.M.S., Vargas, E.A. and de Campos, T.M.P. (2006) On the evaluation of unsaturated flow in a natural slope in Rio de Janeiro, Brazil. Engineering Geology 88, pp. 23-40.

Lumb, P. (1975) Slope failure in Hong Kong. Quarterly Journal of Engineering Geology 8, pp. 31-65.

Troncone, A. (2005) Numerical analysis of a landslide in soils with strain-softening behaviour. Geotechnique 55(8), pp. 585-596. 